\title{
Squamous cell carcinoma arising in hypertrophic lichen planus
}

\author{
Caroline Cecile Pauline Haenen, ${ }^{1}$ Aletta Atje Jacoba Buurma, ${ }^{2}$ Roel Erik Genders, ${ }^{1,3}$ \\ Koen D Quint ${ }^{1,3}$
}

'Department of Dermatology, LUMC, Leiden, The Netherlands ${ }^{2}$ Department of Pathology, LUMC, Leiden, The Netherlands ${ }^{3}$ Department of Dermatology, Roosevelt Clinics, Leiden, The Netherlands

Correspondence to Dr Koen D Quint, k.d.quint@lumc.nl

Accepted 20 June 2018
Check for updates

(c) BMJ Publishing Group Limited 2018. No commercial re-use. See rights and permissions. Published by BMJ.

To cite: Haenen CCP, Buurma AAJ, Genders RE, et al. BMJ Case Rep Published Online First: [please include Day Month Year]. doi:10.1136/bcr-2017224044

\section{SUMMARY}

Hypertrophic lichen planus (HLP) is a chronic T-cellmediated inflammatory disease characterised by pruritic hypertrophic or verrucous plaques on the lower limbs. We report a case of an 87-year-old woman with a 12year history of HLP on both lower legs presenting with malignant transformation of one lesion into a squamous cell carcinoma (SCC). Malignancy developing in cutaneous lichen planus is rare, with less than 50 cases reported in the literature. This case highlights the need to be aware of suspicious changes in long-standing HLP to allow early detection of a developing SCC.

\section{BACKGROUND}

Lichen planus (LP) is an idiopathic mucocutaneous T-cell-mediated disease, characterised by a chronic inflammatory process which leads to destruction of the epidermal basal layer. Hypertrophic lichen planus (HLP) is a chronic variant of LP that most often affects the lower extremities and presents with pruritic, thick hyperkeratotic or verrucous plaques. The lesions tend to be chronic due to repetitive scratching. Chronic venous stasis frequently contributes to the development of HLP on the lower limbs. ${ }^{1}$

Although HLP is a benign disorder, malignant transformation may occur. The incidence of squamous cell carcinoma (SCC) developing in cutaneous LP is estimated to be $0.4 \%{ }^{2}$ The majority of cutaneous SCC occurs in the hypertrophic type of LP located on the lower limbs. ${ }^{2-5}$ Here we describe a case of SCC arising in a long-standing HLP on the lower leg.

\section{CASE PRESENTATION}

An 87-year-old woman was referred to our dermatology department for assessment of a verrucous ulcerated lesion on the right anterior shin. She had a 12-year history of histologically proven HLP on both pretibial areas. During the last 6 months, tumour growth was observed in the HLP lesions on the right anterior shin. There were no additional cutaneous or mucosal lesions. She had been treated with various potent topical corticosteroids with only temporary response. Her medical history consisted of chronic venous insufficiency, hypertension and carotid endarterectomy. She had no history of excessive sun exposure, systemic administration of immunosuppressive drugs, arsenical contact or X-ray exposure at the local site. There was no personal or family history of skin cancer.

On examination, multiple hyperkeratotic erythematous plaques were observed on the bilateral pretibial regions (figure 1) with a verrucous ulcerated growth, measuring $12 \mathrm{~cm} \times 8 \mathrm{~cm}$, on the anterior side above the right ankle (figure 2). Regional lymphadenopathy was absent. There were no LP lesions elsewhere on the body.

\section{INVESTIGATIONS}

Histopathological mapping was performed with four punch biopsies from the hyperkeratotic and verrucous area of the lower right leg and one punch biopsy from the hyperkeratotic area of the lower left leg. The latter showed typical findings of HLP with irregular epidermal hyperplasia and saw-toothed rete ridges, wedge-shaped hypergranulosis, colloid bodies and a dense lymphocytic infiltrate at the dermoepidermal junction. Histopathology from the right lower leg showed irregular epidermal hyperplasia with parakeratosis, a subepidermal lymphocytic infiltrate and a proliferation of atypical keratinocytes with nests of atypical keratinocytes infiltrating deep into the dermis, consistent with SCC (figure 3).

MRI of the right lower leg showed a lesion infiltrating in the subcutis without intramuscular or intraosseous involvement. Chest X-ray and ultrasound of the inguinal lymph nodes showed no abnormalities.

\section{TREATMENT}

The patient was referred to the plastic surgeon for wide surgical excision and reconstruction under general anaesthesia. The hyperkeratotic and verrucous area of the right lower leg was resected with a clinical margin of $1 \mathrm{~cm}$. The skin defect was closed with a split-thickness skin graft from the unaffected right upper leg. The excision specimen showed a well-differentiated SCC with an invasion depth of $5 \mathrm{~mm}$, without perineural or vasoinvasive tumour growth (tumour, node, metastases stage II). All surgical margins were free of tumour.

\section{OUTCOME AND FOLLOW-UP}

The patient is seen for regular oncological check-ups. At the most recent follow-up, 9 months postoperatively, she had no sign of recurrence of SCC. 


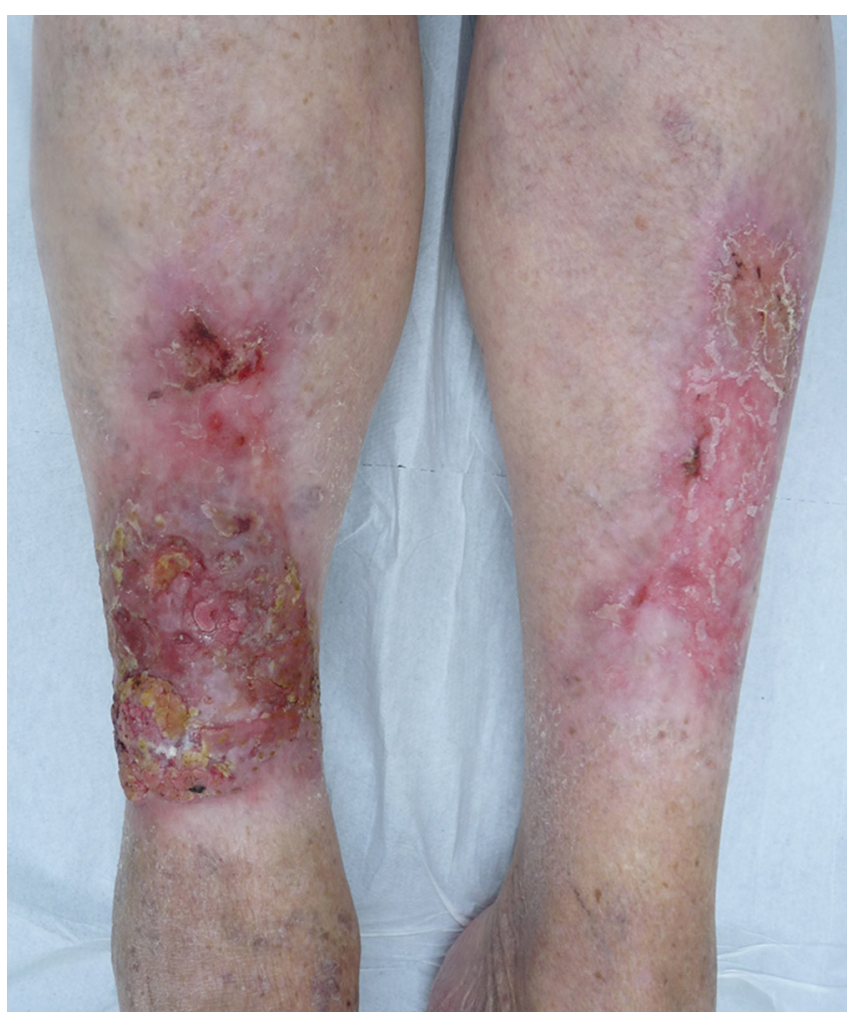

Figure 1 Clinical photograph of the hyperkeratotic and verrucous erythematous plaques on the bilateral pretibial regions.

\section{DISCUSSION}

Malignant transformation of cutaneous LP is rare. A large epidemiological study of 2071 Swedish patients with LP showed an increased risk for oral SCC, but not for cutaneous malignancy. In this study, only six SCCs of the skin were observed in an average period of 9.9 years. ${ }^{3}$ The incidence of SCC associated with cutaneous LP is estimated to be $0.4 \% .^{2}$ More than $56 \%$ of the malignant neoplasms reported in cutaneous LP lesions arise in the hypertrophic variant of LP below the knee, similar to our case. ${ }^{2-10}$ This could be explained by the fact that patients with chronic pruritic dermatosis tend to scratch the lower part of their legs intensely, causing chronic inflammation. Chronic

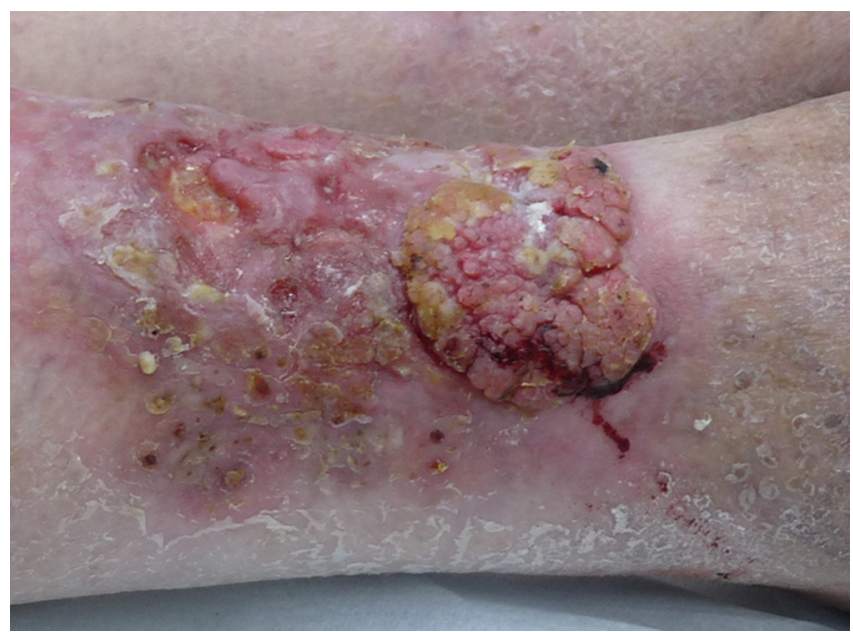

Figure 2 Clinical photograph showing an ulcerated verrucous growth on hypertrophic lichen planus on the anterior side above the right ankle.

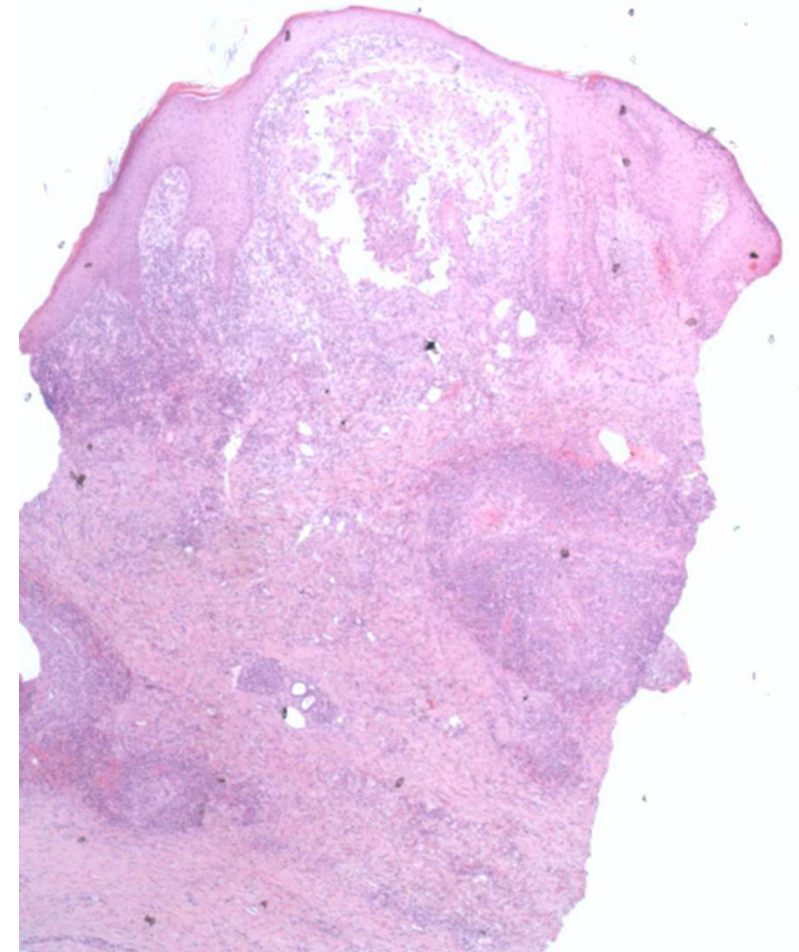

Figure 3 Histopathology (x40 magnification) of a punch biopsy from the right shin hyperkeratotic plaque showed irregular epidermal hyperplasia, a subepidermal lymphocytic infiltrate and a proliferation of atypical keratinocytes with nests of atypical keratinocytes infiltrating deep into the dermis, consistent with squamous cell carcinoma .

inflammation and accelerated cellular turnover in LP are thought to play a role in cancer development. ${ }^{23}$

Chronic venous insufficiency frequently contributes to the development of HLP. ${ }^{1}$ The medical history of chronic venous insufficiency may have played a role in the development of HLP in our patient, with subsequent development of SCC in the area of chronic inflammation. Furthermore, a history of arsenical or radiation treatment has been reported as possible risk factors in the development of SCC in patients suffering from LP. ${ }^{4}$ Our patient did not undergo exposure to arsenic or radiation, but she did have chronic inflammation from the HLP plaque for 12 years prior to SCC diagnosis. This is corresponding with previous studies reporting an average latency period of 12 years between the onset of HLP and the development of SCC. ${ }^{35}$

The most prevalent treatment modality for SCC arising in HLP is wide local excision. Systemic retinoids, radiation therapy, electrodesiccation and curettage are other types of treatment reported in literature. ${ }^{5}$ Treatment of HLP may reduce

\section{Learning points}

- Hypertrophic lichen planus (HLP) is a chronic variant of lichen planus, presenting with pruritic hyperkeratotic or verrucous plaques.

- Malignant transformation of cutaneous lichen planus is rare.

- The majority of squamous cell carcinoma is found to occur in HLP lesions located on the lower limbs.

- Consider malignancy in long-standing proliferative and ulcerating areas of HLP.

- Patients with HLP should be followed up regularly. 
the risk of malignancy by reducing the inflammation. Most SCC arising in HLP are well-differentiated and localised lesions, ${ }^{5}$ however two cases of metastatic SCC from HLP lesions have been reported. ${ }^{910}$ Further examination did not show metastatic disease in our patient.

This case illustrates the need to be aware of malignant change when a proliferative ulcerating area appears in, particularly long-standing, lesions of HLP located on the legs. These patients should undergo regular follow-up with periodic biopsies to exclude malignancy.

Contributors CCPH: first author of article, analysis and interpretation of data. AAJB: analysis of histology, co-author, critical revision of the work, final approval of the version to be published. REG: co-author, critical revision of the work, final approval of the version to be published. KDQ: co-author, critical revision of the work, final approval of the version to be published.

Funding The authors have not declared a specific grant for this research from any funding agency in the public, commercial or not-for-profit sectors.

Competing interests None declared.

Patient consent Obtained.

Provenance and peer review Not commissioned; externally peer reviewed.

\section{REFERENCES}

1 Bolognia JL, Jorizzo JJ, Schaffer JV, et al. Dermatology. 3rd edn. London: Elsevier, 2012.

2 Singh SK, Saikia UN, Ajith C, et al. Squamous cell carcinoma arising from hypertrophic lichen planus. J Eur Acad Dermatol Venereol 2006;20:745-6.

3 Sigurgeirsson B, Lindelöf B. Lichen planus and malignancy. An epidemiologic study of 2071 patients and a review of the literature. Arch Dermatol 1991;127:1684-8.

4 Bonnekoh B, Kuhn A. [Squamous epithelial cancer in lichen ruber hypertrophicus--a case report with a review of the literature]. Z Hautkr 1986;61:394-402.

5 Knackstedt TJ, Collins LK, Li Z, et al. Squamous cell carcinoma arising in hypertrophic lichen planus: a review and analysis of 38 cases. Dermatol Surg 2015:41:1411-8.

6 Krasowska D, Kozłowicz K, Kowal M, et al. Twice malignant transformation of hypertrophic lichen planus. Ann Agric Environ Med 2012:19:787-9.

7 Campanati A, Marconi B, Penna L, et al. A case of hypertrophic lichen ruber planus of the leg complicated by a squamous cell carcinoma. Int J Dermatol 2003;42:415-6.

8 Manz B, Paasch U, Sticherling M. Squamous cell carcinoma as a complication of longstanding hypertrophic lichen planus. Int I Dermatol 2005;44:773-4.

9 Ardabili M, Gambichler T, Rotterdam S, et al. Metastatic cutaneous squamous cell carcinoma arising from a previous area of chronic hypertrophic lichen planus, Dermatol Online J 2003:9:10.

10 Tong LX, Weinstock MJ, Drews R, et al. Widely metastatic squamous cell carcinoma originating from malignant transformation of hypertrophic lichen planus in a 24-year-old woman: case report and review of the literature. Pediatr Dermatol 2015:32:e98-e101.

Copyright 2018 BMJ Publishing Group. All rights reserved. For permission to reuse any of this content visit http://group.bmj.com/group/rights-licensing/permissions.

BMJ Case Report Fellows may re-use this article for personal use and teaching without any further permission.

Become a Fellow of BMJ Case Reports today and you can:

- Submit as many cases as you like

- Enjoy fast sympathetic peer review and rapid publication of accepted articles

- Access all the published articles

Re-use any of the published material for personal use and teaching without further permission

For information on Institutional Fellowships contact consortiasales@bmjgroup.com

Visit casereports.bmj.com for more articles like this and to become a Fellow 